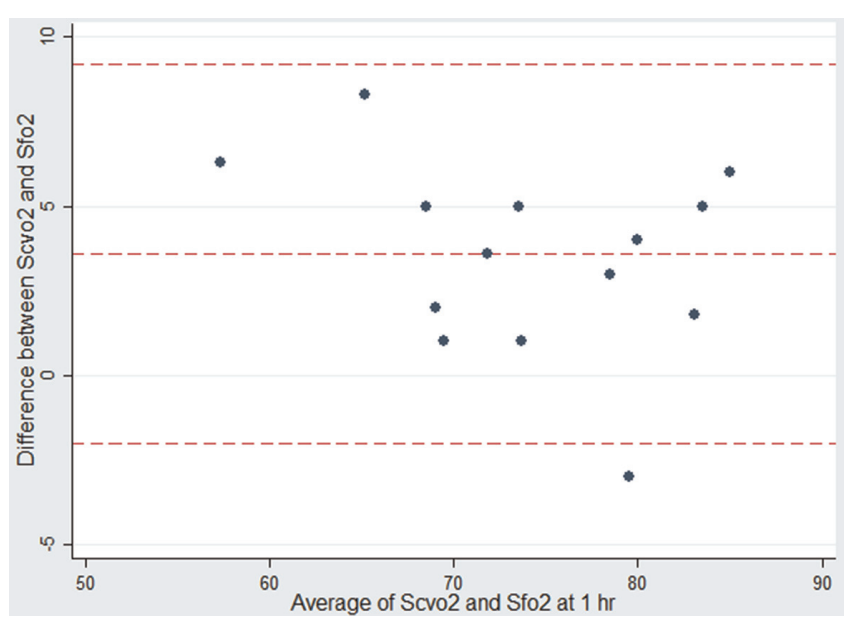

Abstract 0-117 Figure 1 Agreement between $\mathrm{ScvO}_{2}$ and $\mathrm{SfvO}_{2}$ values at $1 \mathrm{~h}$

Background and aim Femoral vein catheterization is very commonly performed while managing children with septic shock. However, the agreement between superior venal caval $\left(\mathrm{ScvO}_{2}\right)$ and femoral venous oxygen saturation $\left(\mathrm{SfvO}_{2}\right)$ has not been reported in children till date. Our aim was to evaluate the agreement between $\mathrm{ScvO}_{2}$ and $\mathrm{SfvO}_{2}$ values.

Methods Children with septic shock in whom femoral vein catheter was inserted before shifting to the ICU were eligible. Paired blood samples from subclavian/Internal jugular vein and femoral catheters were drawn simultaneously after initial fluid resuscitation in these children and analysed. Agreement was assessed by Bland and Altman (BA) analysis. The study was approved by IRB.

Results A total of 32 patients were enrolled. The mean $\mathrm{ScvO}_{2}$ and $\mathrm{SfvO}_{2}$ were $72.3 \%$ and $76 \%$ respectively ( $\mathrm{p}<0.001$ ). BA analysis showed relatively poor agreement between $\mathrm{ScvO}_{2}$ and $\mathrm{SfvO}_{2}$ with mean bias of 3.6 and $95 \%$ limits of agreement of 1.95 to $9.25(\mathrm{r}=-0.28, \mathrm{p}=0.14)$ (Figure 1$)$. In general, $\mathrm{SfvO}_{2}$ values were higher than $\mathrm{ScvO}_{2}$ values with 14 of the 32 children having values $\geq 5 \%$. The $\mathrm{SfvO}_{2}$ had poor sensitivity (45.5\%) but $100 \%$ specificity for detecting low saturations. The PPV was $100 \%$ and the NPV was $77.8 \%$. As SfvO2 values were generally higher than $\mathrm{ScvO}_{2}$ values, we tried a higher cut-off for $\mathrm{SfvO}_{2}$ to detect low mixed venous saturations. With a $\mathrm{SfvO}_{2}$ cut off of $72 \%$, the sensitivity and specificity were both $100 \%$.

Conclusions A higher cut off of $72 \%$ for $\mathrm{SfvO}_{2}$ may be used in place of $\mathrm{ScvO}_{2}$ in situations where $\mathrm{ScvO}_{2}$ estimation has failed or is impractical. Our study findings however, need further validation.

\section{0-118 HIGH PREVALENCE OF CYTOMEGALOVIRUS PROTEINS IN SURGICAL SPECIMENS OBTAINED FROM INFANTS WITH NECROTIZING ENTEROCOLITIS, BOWEL PERFORATION OR BOWEL STRICTURE}

${ }^{1} \mathrm{~S}$ Omarsdottir, ${ }^{2} \mathrm{M}$ Agnarsdottir, ${ }^{3} \mathrm{~A}$ Orrego, ${ }^{1} \mathrm{E}$ Skantz, ${ }^{4} \mathrm{M}$ Vanpée, ${ }^{1} \mathrm{~A}$ ${ }^{1} \mathrm{C}$ Söderberg-Nauclér. 'Department of Medicine Solna, Karolinska Institute, Stockholm, Sweden; ${ }^{2}$ Institute of Immunology Genetics and Pathology, Uppsala University, Uppsala, Sweden; ${ }^{3}$ Department of Clinical Pathology and Cytology, Karolinska University Hospital, Stockholm, Sweden; ${ }^{4}$ Department of Women's and Children's Health, Karolinska Institute, Stockholm, Sweden

10.1136/archdischild-2014-307384.185
Background and aims Necrotizing enterocolitis (NEC) is a frequent cause of neonatal surgical emergency. The pathogenesis of the disease is incompletely understood. Postnatal cytomegalovirus (CMV) infection can present clinically as NEC and be related to bowel perforation or intestinal stricture in the neonate. The aim of this study was to evaluate the presence of CMV infection in intestinal samples obtained from infants with these conditions. Methods Surgical specimens from infants diagnosed with NEC, bowel perforation or intestinal stricture during year 1997-2009 were collected from the pathology departments at Karolinska University Hospital and Uppsala University Hospital. The intestinal samples were retrospectively analysed for CMV Immediate Early Antigen (CMV-IEA) and CMV Late Antigen (CMV-LA) by immunohistochemistry.

Results Sixty-six intestinal specimens from 47 preterm infants and 10 full term infants were collected. The median gestational age of the infants was 27.9 weeks and their median birth weight was 1015 grams. The pathological diagnoses were NEC ( $\mathrm{n}=$ 36), NEC and intestinal perforation $(n=12)$, intestinal perforation $(n=12)$, sequel after NEC $(n=3)$ and unspecific changes $(\mathrm{n}=3)$. CMV-IEA and CMV-LA was detected in $85 \%$ and $61 \%$ of the intestinal tissue samples, respectively. Of these samples, $71 \%$ and $38 \%$ were classified as having a high-grade $(\geq 25 \%)$ CMV infection.

Conclusions CMV proteins were detected in the vast majority of intestinal specimens obtained from infants diagnosed with NEC, bowel perforation or intestinal stricture. These findings support a possible role of CMV in the pathophysiology of NEC and other surgical conditions in the neonate.

\section{Teaching Using Simulation}

\section{0-119 CAPNOGRAPHY IMPROVES NEONATAL FACE MASK VENTILATION}

G Hawkes, M Kenosi, CA Ryan, EM Dempsey. Department of Paediatrics and Child Health, University College Cork, Cork, Ireland

\subsection{6/archdischild-2014-307384.186}

Background Assessment of effective positive pressure ventilation (PPV) in neonatal mask ventilation can be difficult.

Objectives To determine which was the most effective method of providing PPV: a T-piece resuscitator (TPR) with no device attached (ND), a TPR containing an in line $\mathrm{CO}_{2}$ detector (NeoStatCO $\left.\mathrm{C}_{2}<\mathrm{Kg}^{\circledR}\right)(\mathrm{COD})$ or a TPR with a capnography device attached (CAP).

Methods This was a randomised crossover trial. Neonatal trainees were randomly assigned to each method (ND, COD or CAP). They then alternated methods such that all participants provided PPV with each method for a period of $2 \mathrm{~min}$ on a $\mathrm{CO}_{2}$ producing mannequin. Participants were video recorded to determine the amount of effective ventilations delivered, and the overall percentage efficacy of each method. Informed consent was obtained.

Results 23 paediatric trainees provided a total of 6035 ventilations and $91.1 \%$ were deemed to be effective. There was no statistically significant difference between the percentage efficacy of breaths delivered between the three methods. Percentage of effective ventilations with ND, COD and CAP were $90.8 \%$, $90.9 \%$ and $91.8 \%$ respectively. $15(65 \%)$ of the trainees indicated a preference for the COD method and 8 (35\%) for the CAP method. No trainees indicated a preference for the ND 
method. The CAP method was most likely to provide the highest efficacy per participant $(47.8 \%)$.

Discussion Methods of $\mathrm{CO}_{2}$ monitoring during manual ventilation with a facemask results in greater efficacy of delivered breaths. Whilst the NeoStat device was the preferred device by the majority of participants, the highest efficacy was achieved with the capnography device. Capnography may enhance facemask ventilation in the clinical setting and future trials are now required.

\section{0-120 CARDIAC COMPRESSION QUALITY DETERIORATES WITH INCREASING COMPRESSION RATE DURING PRETERM RESUSCITATION SIMULATIONS: A NEW PRETERM SIMULATION TRAINER}

S Tan, N Batey, D Sharkey. Academic Child Health School of Medicine University Hospital, University of Nottingham, Nottingham, UK

\subsection{6/archdischild-2014-307384.187}

Background Effective cardiac compressions (CC) with a full relaxation phase ensure adequate coronary artery blood flow by increasing coronary perfusion pressure (CPP). CC during neonatal resuscitations are rare thus requiring them to be practiced in simulation training. No studies have explored the efficacy of CC during preterm simulations.

Aims 1) Develop a preterm manikin simulation system for CC training

2) Define key measures of effective CC in this preterm simulation

Methods We used the Laerdel term and LifeForm preterm ( $\sim 25$ week gestation, $0.8 \mathrm{~kg}$ ) manikins with an in-house developed calibrated CC measurement system (accuracy $\pm 3 \%$ ). NLS trained neonatal staff randomly performed 2 finger or 2 thumb (circling) CC resuscitation simulations. Compression rate, depth $(>1 / 3$ AP diameter of chest) and release $(>75 \%$ release of compression distance) were measured.

Results 30 participants each performed 8 simulations (total 23,340 CC). Median CC rate was 93/min(IQR 84-111). For both term and preterm simulations, the 2 thumb technique

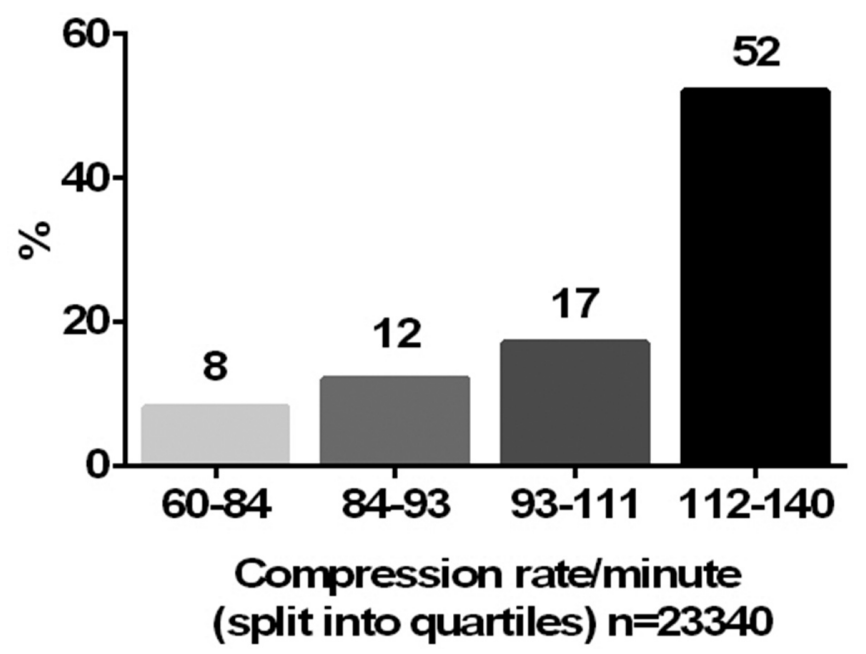

Abstract 0-120 Figure 1 Percentage of compressions with inadequate release during the simulated cardiac compressions achieved more adequate depth CC than the 2 finger technique $(\mathrm{P}<0.0001)$. Incomplete release was significantly worse in the 2 thumb group especially in the preterm simulations. With increasing CC rate, incomplete release increased significantly from $8 \%$ in the $60-84 \mathrm{CC} / \mathrm{min}$ rising to $52 \%$ in the $112-140 \mathrm{CC} / \mathrm{min}(\mathrm{P}$ $<0.0001$, see Figure).

Conclusion We have developed a useful CC preterm training simulator with important feedback measures. These simulations demonstrate the quality of CC decreases with increasing rate above NLS recommended guidelines. In clinical practice, this would reduce CPP and delay the restoration of an adequate cardiac output.

\section{Two Different Views on Early Nutrition}

\section{0-121 LUNG FUNCTION IN 6 YEAR OLD CHILDREN BORN VERY PRETERM AND FED DIFFERENT DIETS POST DISCHARGE}

L Toftlund, L Agertoft, S Halken, G Zachariassen. HC Andersen Childrens Hospital, University Hospital Odense, Odense, Denmark

\subsection{6/archdischild-2014-307384.188}

Background Research has shown that being born preterm may affect lung capacity later in childhood. It is unknown if type of early nutrition influences lung capacity and the risk of developing asthma in childhood.

Aim Was to investigate type of early nutrition and impact on lung function and possible risk of developing asthma among 6 year old children born very preterm.

Method A prospective, randomised, interventional multicentre study on nutrition of a preterm birth cohort has been established and described previously. Inclusion criteria were gestational age $\leq 32$ weeks. From hospital discharge to 4 month corrected age, the children received three types of nutrition: A: Human milk (HM) B: HM enriched with fortifier (HMF) C: Preterm formula (PF). At the age of 6, the children performed an occlusion test (Rocc) and a lung resistance test (SRtot).

Results 277 children are included in this project [SH1]. So far 96 children have performed the lung function tests (Group A: 31 B: 29 C: 36 respectively). The results (mean) from the Rocctest were very similar comparing the groups with no significant differences: A: 1.05 B: 1.05 C: $1.04\left(\mathrm{kPa}^{*} \mathrm{~s} / \mathrm{L}\right)$. The SRtot test showed that group $\mathrm{B}$ and $\mathrm{C}$ had a significant lower value compared to group A: A $1.21 \mathrm{~B}: 0.98 \mathrm{C}$ : 1.01 (kPa*s). P-value= 0,017 when comparing A and C, p-value $=0,003$ when A compares to B.

Conclusion This preliminary result indicates that children who received exclusively breastfeeding have better lung function/lung resistance compared to not exclusively breastfed infants at the age of 6 .

\section{0-122 TARGET FORTIFICATION (TFO) OF BREAST MILK WITH FAT, PROTEIN AND CARBOHYDRATES FOR PRETERM INFANTS: INFLUENCE OF COMMERCIALLY AVAILABLE FORTIFIERS ON MACRONUTRIENT INTAKE}

N Rochow, G Fusch, A Ali, C Fusch. Pediatrics, McMaster University, Hamilton, Canada 